\title{
Presence and absence of the belated witness in two short stories by Mavis Gallant
}

\author{
Joseph BaLlan
}

\begin{abstract}
This essay extends Michael Levine's theory of the 'belated witness' as an approach to the question of how Holocaust survival is represented in literature, by considering how the absence of such a witness is made perceptible in two stories by Mavis Gallant. Much of Gallant's short fiction critically analyzes various aspects of post-war western European cultures, but the two stories considered here ('The Old Place' and 'Old Friends') are unique in her published fiction in that they feature concentration camp survivors as main characters. According to Levine, the 'belated witness' is a narrative figure, different to the survivor him or herself, who enables and supports testimony to trauma. This essay argues that this kind of figure is absent in both stories by Gallant, but that rather than a banal absence (i.e., simply missing from the dramatis personae), this absence is significant (i.e., is the conclusion of Gallant's analysis).
\end{abstract}

Beginning with her earliest stories, published in the 195 os, the landscapes of post-war Europe, populated by refugees, displaced persons and soldiers returning to civilian life, have been among the central concerns of Mavis Gallant's fiction. As a young journalist at the Standard, one of Montreal's English-language weeklies, now defunct, the late Canadian writer had been among the earliest in Canada to see the photographic record of the liberated concentration camps, and at the newspaper where she worked, she argued, unsuccessfully, for presenting these photographs to the Canadian public in a way that would be neither sensationalist nor supportive of nationalistic militarism. It was the first time her journalistic writing had been rejected by the newspaper's editor. This experience seems to have been formative for her. Twenty years after her time at the Standard, she reports having become convinced that 'the concentration camp experience, its lesson, its warning, had become kitsch' (quoted in Keefer I 989: I 58). This conviction led her to undertake an investigation, by means of fiction and by travelling to (West) Germany frequently during the early i 960 , not into the 'concentration-camp experience' itself, but into the kinds of cultural processes, embedded in everyday life and relationships, that might make this sort of kitschification possible. This would be an investigation into what Neil Besner has called, in his monograph on Gallant, the state of 'paralyzed bewilderment' ( 1988 : 70) with which Germans dealt with the recent history of their nation. Alexander and Margarete Mitscherlich famously termed this condition 'the inability to mourn', although Gallant's German stories also attempt to speak about what the writer calls 'fascism's ... little possibilities within people' (quoted in Besner r 988: 70), and specifically within the apparently banal, taken-forgranted structures and settings of everyday life in Western cultures more generally. The stories would then be both about cultural amnesia and the structures of repressed memory, as well as about the permanent possibilities of the returns of fascism. 


\section{The Old Place}

HI HOwsr they had abandoned was cightcen miles from Poughkeepsie, in a valley almost deserted because of a bad road. Traffic bad been diverted to the new highway in 1905; scarcely anything

'The Old Place' was published in Texas Quarterly in 1958, and never republished by Gallant.

In her own monograph on Gallant, Janice Kulyk Keefer designates the writer of these works a 'belated witness' to mass murder (I988: I 58 ). These words were written in I 989 , almost two decades before Michael Levine developed a psychoanalytically informed theory of the 'belated witness' as an approach to Holocaust literature (2006). Gallant's status as 'belated witness' would be as witness to the delayed effects of the catastrophe of National Socialism on the level of culture and interpersonal relationships. Or, perhaps more accurately put, she would have been a witness to the actualisation of certain possibilities of fascism, to the after-effects of these actualisations, and to the ongoing possibility of their repetition. In the same interview to which I have referred, she also reveals, 'I had the feeling that in everyday living I would find the origin of the worm - the worm that had destroyed the structure' (quoted in Besner I 988: 68), the worm being something like the psychology that makes political fascism possible, and the structure being the German cultural heritage which the young journalist Gallant had admired and which her editors had demonised. She explains here that, by means of fiction about everyday life in postwar settings, she wants to find the 'origin' of those phenomena she finds both troubling and still present. This explanation appears to reverse the temporal chain of causality, and it makes clear that such historical chains do not constitute her primary interest. Instead, the scene and the position of belatedness, as emblematised by the figure named in a representative title from this project, 'The Latehomecomer', is the object of her investigation and writerly interest.

In this article, I wish to focus on two stories in which this position of belatedness determines the interactions of camp survivors with civilians. The more interesting of the two stories for my purposes here is 'The Old Friends', which appeared in The New Yorker magazine in I969 and later in the 1974 collection, The Pegnitz Junction. 'The Old Friends' is the only one of Gallant's so-called German stories to include a camp survivor as a character, namely the Jewish actress Helena, who in the years after the war has become a film star in West Germany. Before the so-called German stories of the late r 960 s and early r 97os, though, Gallant had written another story involving a concentration-camp survivor, published in 1958 as 'The Old Place', in the rather more obscure Texas Quarterly and, interestingly enough, never republished anywhere, not even in Gallant's definitive Collected Stories. Before moving on to a discussion of 'The Old Friends', I wish to briefly consider why it might have been that Gallant declined to republish this earlier piece, which has not been discussed in any of the secondary literature on Gallant's work.

'The Old Place' does not fit into the project of the later stories alluding to the Holocaust if these latter are preoccupied with what Besner describes as a specifically German state of 'paralyzed bewilderment'; 'The Old Place' is concerned with an American version of the same. It is concerned with a rather different, but not wholly unrelated, sort of inquiry or investigation. The identity of the titular 'old place' is not singular: it is at once a ruined, bucolic family home in New York's Hudson Valley and the concentration camps of Europe, also in ruins now. The story is about the ways in which such 
'old places' resonate in time, but also about how the memories of such (radically different, in the case of this story) places as they are instantiated in separate individuals can interfere with each other, as it were, and obstruct intersubjective encounter. Each of the three main characters is isolated from the others in different ways, all of which can be traced back to differing memories of non-identical 'old places'. Danielle Schaub analyses narrative methods in Gallant's stories (including 'The Old Friends') by which the author investigates 'how people cannot relate to others truthfully' (2002: 32). While this is one of the overarching themes of Gallant's oeuvre (in which there are precious few examples of relationships characterised by mutual understanding), in this paper, I seek to show that the specific form taken by the non-truthful relations in the two stories under consideration can be regarded as the absence of the belated witness, or as the failure of the characters to serve in the capacity of the belated witness. What I mean by this is spelled out in greater detail below, in the discussion of 'The Old Friends'.

The odd centre of 'The Old Place' is Dennis, an almost improbably dull, dense, helpless twenty-something American man-child whose mother marries a concentration-camp survivor (these are the three main characters). This crucial fact about the older man's life is, significantly, buried in a long paragraph that introduces him as an 'immigrant doctor' of uncertain ethnic background (Gallant I958: 70): 'Talk about himself tumbled like a waterfall, but even the enormous number of facts he threw out left him mysterious, difficult to place'. Even though the omniscient third-person perspective from which the story is narrated knows exactly where to place him, this 'difficulty' is foregrounded in the characterisation of him, and it has, in the end, something to do with the perspectives and problems of each of the story's main characters. As Mary Condé writes in her analysis of 'Malcolm and Bea', another story which touches upon rather similar issues, without putting a camp survivor on the stage of the narrative, as it were, 'it is one of Gallant's achievements as a storyteller that the shifts from first to third person in her narratives brilliantly suggest the illogical and self-interested interpolations of individuals into a clear and rational discourse on history' (Condé 200I: I70). The introduction of the survivor Meyer is his name - continues: 'His past life gloated over their heads, tantalizing and brilliant, like a cluster of escaped balloons' (Gallant I958: 70). Besner notes that Gallant prefers similes like these to metaphors, because of their greater effectiveness as a means of irony (I 988 : I 5 I), and Schaub claims more specifically that, in Gallant's stories, 'similes generate ironic readings that reveal the characters' unawareness or their own situation' (1998: 53), a function that is certainly at work in this particular sentence. The characterisation of Meyer's presence as like a 'brilliant ... cluster of escaped balloons' is almost grotesquely impertinent in light of the fact that, remarkably, follows it: 'He had been in a concentration camp' (Gallant I958: 70). The very sequence of the description in this paragraph anticipates what we will call the inability to witness' in our analysis of 'The Old Friends', though one can also detect in this story the more familiar phenomenon of an 'inability to mourn': Meyer is obsessed with amassing historical data about the camp system, and this objectification of (his own) historical experience can be viewed as a way of not coming to terms with the catastrophes of his own life. He wants to spend a summer in Europe revisiting the sites of the several camps where he was interned, as well as his daughter, who is also a survivor. The narrator tells us that he wanted to 'show [the camps] to his wife' (ibid. 72), perhaps to engage her as a belated witness to his experiences there, about which, by story's end, we know next to nothing. The dull, sullen Dennis comes along for the ride, but skips the visit to the camps.

Like 'The Old Friends', this story is haunted 


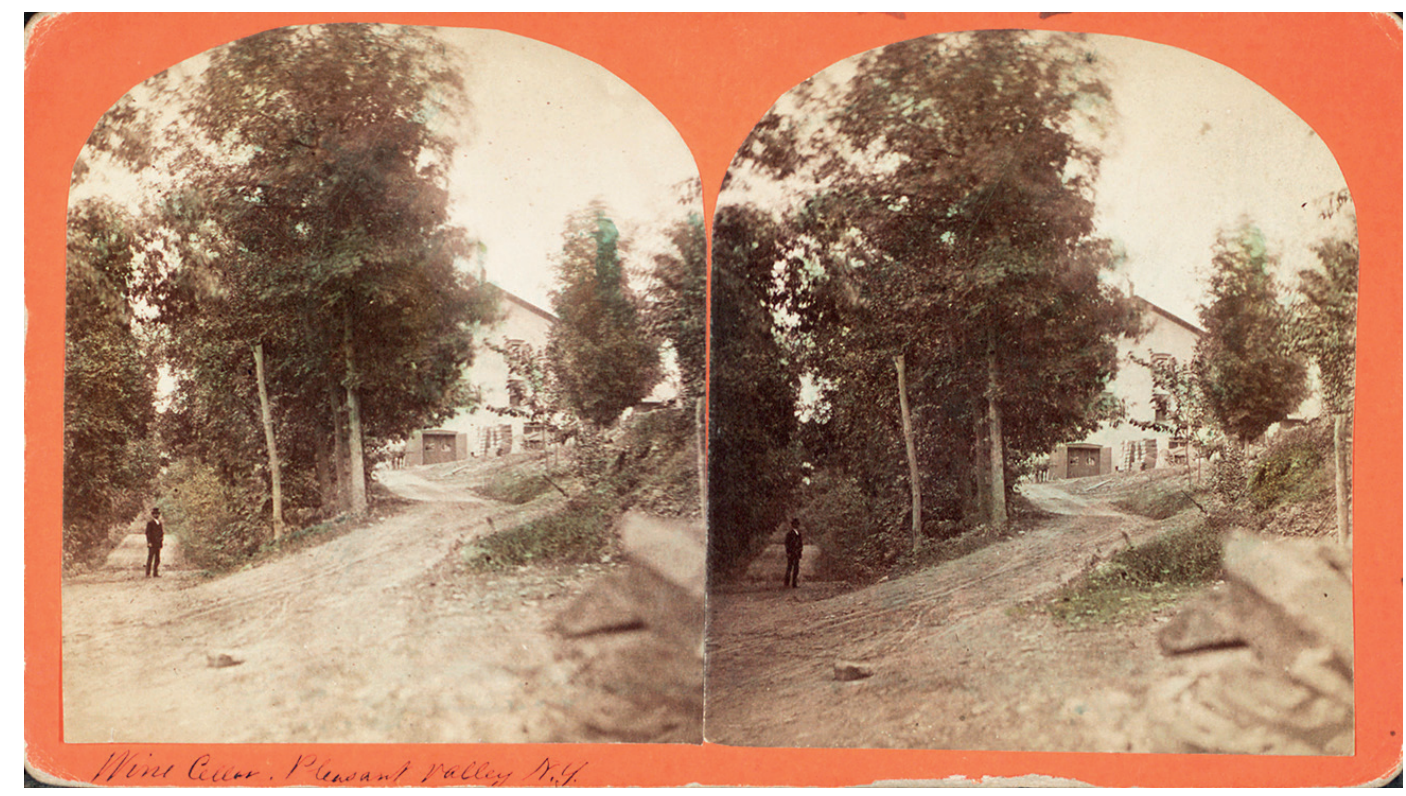

Pleasant Valley, New York, is the same approximate distance from Poughkeepsie as the unnamed town in 'The Old Place'.

by the distinct absence of a belated witness, of anyone who enables Meyer to tell his own story and to be a testimonial support for any belated effects the trauma might have on his telling of it. Dennis, emblem of the post-war American young male, is pathetically uncomprehending, whereas his mother is mired in a vague and narcissistic sense of guilt whose self-referentiality clouds her understanding of Meyer's situation (Dennis sees the guilt as 'unnecessary', which would be its own, separate but linked, sort of problem; Gallant i958: 74-5). Even when the mother figure does in fact attempt to draw the story (apparently for the first time) out of Meyer and his daughter while the four of them sit in the latter's Geneva apartment, her own anxiety, presumably an effect of her feelings of guilt, seems to overshadow the telling of the story itself. The two American characters would stand rather conveniently for a generational difference visà-vis the Holocaust, in North America at least. The climactic scene takes place in the Geneva apartment, where Dennis's mother fails to perceive that the visit to the camps and the visit to the daughter are, in Meyer's mind, closely connected to each other. She expresses pity for her robust husband, but regards the more visibly traumatised, socially incapacitated daughter with revulsion, as a 'monster' lacking in 'natural feelings' (ibid. 76). The unnamed mother fails to make the connection between her new husband's ordeal and her ste-daughter's trauma, a connection that continues to affect their relationship. This leads to the question of why this story was not reprinted in any collection of Gallant's stories. To begin with, it is difficult to imagine this same character (the mother) feeling such pity for the Meyer character and such callous contempt for the daughter. There is, more generally, a sketchy quality to these characters, a quality of not being fully realised, together with an at once simplistic and, in the end, unilluminating parallel drawn between 'the old place' of the American mother and son - a family estate in New York state - and the old place of the father and daughter - the camp (one senses that Gallant herself was alert to this quality, in the ironic comment by the mother upon hearing 
Meyer's daughter's story of the aftermath of the war: 'Oh, Dennis ... and we sat there in our lovely garden, not doing a thing for anybody', ibid. 75). It is not hard to imagine why Gallant chose not to republish this story. Mavis Gallant is one of the short-story form's undisputed masters, and this particular story is conspicuous in that it does not exemplify this mastery (though there are, undeniably, occasional flashes of her customary brilliance). It does, however, indicate her (at the time of its composition) nascent interest in how fiction could be used to investigate recent history - not in a mode of memory, but above all in observing its ongoing cultural and psychological effects, and it demonstrates that this interest extends beyond the psychology of fascism as such - which most of her critics have emphasised. All her fiction having to do with the Holocaust regards the genocide from an oblique angle. In both 'The Old Place' and in the story which I will discuss below, the form that this obliqueness takes is a depiction of the absence from their inter-subjective worlds of a belated witness, an absence which her narrative art makes palpable.

The book by Michael Levine, mentioned above, is concerned not only with belatedness, but also with testimony and witnessing. The psychic trait of post-war European and also North American cultures that Gallant scrutinises in the two stories discussed in the present essay is an inability, not to mourn, but to witness, and furthermore to bear witness to the witness. This would also be an inability or unwillingness to listen - an inability or unwillingness that would not be, according to Gallant, a trait unique to Germany among wartime and post-war cultures. ${ }^{1}$ In 'The Old Friends', one of the clearest

1 What Gallant explores in these two works and others is an inability or unwillingness similar to that which Hannah Arendt noted already in 1943 with respect to the situation of refugees in their host countries, namely in indices of this inability may be found in the very style of the story, which is in turn a function of its narrative voice: cool, detached, ironic, as in so much of Gallant's work. In her essay 'What is style?' Gallant writes, 'Style is inseparable from structure, part of the conformation of whatever the author has to say ... content, meaning, intention and form must make up a whole, and must above all have a reason to be' (1986: 107). In the case of this story, the dispassionate style, the absence of anything overwhelmingly violent or traumatic breaking through the surface of the prose, seems to be a function of the fact that no-one in the world of the story is capable of withstanding whatever violence and trauma might be contained in, and unleashed by listening to, the survivor's story. No-one seems capable of bearing witness to the witness. This would be the story's 'reason to be', to use Gallant's phrase.

Yet the few mentions of the fact that the survivor, whose name is Helena, experienced life in multiple concentration camps, and that her mother and grandmother did not survive this ordeal, are made all the more sudden, all the more striking, by appearing against the backdrop of an otherwise cool, even light narrative tone. This is exactly how such references to the camps are experienced by the other 'old friend' referred to in the story's ironic title, an unnamed police commissioner, namely as 'wounding thing[s]' (Gallant r 974: 93) and, even more, as attacks on him that come out of nowhere, inexplicable in light of his many kindnesses to her. Unlike most of the other German stories, 'The Old Friends' features only the barest of plots, occasioned by the commissioner's having

her essay 'We Refugees', in which she writes, 'how often we [refugees] have been told that nobody likes to listen to all that ... apparently nobody wants to know that contemporary history has created a new kind of human beings - the kind that are put in concentration camps by their foes and in internment camps by their friends' (2007: 265). 
invited Helena and her young son to join him for a pleasant afternoon tea at a garden restaurant outside Frankfurt; the main thing seems to be a sketching of a relationship, at the center of which, as Lesley Clement points out in her reading of the story, is 'the lie in which the police commissioner trusts: that they are not simply "old friends," but "have been friends forever" (2000: I42). The conversations between the two friends are related by a narrator who narrates from a third-person perspective, but who occasionally has selective omniscience when it concerns the thought processes of the two main characters (primarily those of the police commissioner, it should be noted). In the conversations, each reference by Helena to the camps or to her dead family is taken by the commissioner in a narcissistic mode; that is to say, he takes such moments not as his friend's attempts to tell her story, to find an ear that could bear them, but as symptomatic of something amiss in their friendship, perhaps the result of some social misstep or mistake on his part. It does not occur to the commissioner that he could be mis-taking his friend's efforts at communication in another way entirely, but it is precisely such mis-taking (that is, taking the wrong way, misunderstanding) that reveals one of the two key components of this story's portrayal of the absence of what Levine calls 'belated witnessing'.

We shall come to the second component in a moment, but first, let us consider this notion of the belated witness. ${ }^{2}$ In his book The Belated Witness: Literature, Testimony, and the Question of Holocaust Survival, Michael Levine interrogates conceptions of testimony that assume that the act of testimony simply expresses a story that already exists in the witness, who would serve as the story's epistemological guarantor. Levine

2 I use Levine's notion of belatedness, as presented in this paragraph, as a means of interpreting Gallant on related issues in Ballan (2015: I 72-92). shifts the focus to the acts of listening and testifying, depicting a 'space of transmission as the place where the knowing [of a traumatic event] first takes place, where cognizance of the event is belatedly given birth to (2006: 5 ). In shifting the focus in this way, Levine aims to demonstrate that the person who listens to testimony, in the words of Dori Laub, 'can become the enabler of testimony - the one who triggers its initiation, as well as the guardian of its process and of its momentum' (1992: 58), but Levine wants to show, in addition, that the listening subject also thereby becomes implicated in the belated effects of trauma, and specifically the ways in which the space of temistony allows for acting out and potentially also working through the traumatic occurrence which, as in all psychoanalytic accounts of trauma, will not yet have been adequately 'taken in' or processed by the survivor. The listener - whether it is a fictional character or the author herself - is addressed by something in testimonial narratives which, according to Levine, 'exceed [the survivor's] capacity to access and relate'. This address is inseparable from an ethical obligation: the 'supplementary' or 'belated' witness, the one who bears witness to the witness, "implicitly commits himself to the task of assuming co-responsibility for an intolerable burden ... the witness to the witness helps to transform ... traumatic memories into social acts, into narrative memories addressed to others' (Levine 2006: 7). Again, this transformation can take place within the fictional world, or outside it.

In light of this theoretical account, it can be claimed that, in the world of 'The Old Friends', no-one seems willing or able to assume such responsibility (in 'The Old Place', this statement would also be true of Dennis, while his mother's anxiety would also be a way of evading responsibility). That which seems to block the capacity for witnessing in the commissioner is a complicated question which I will attempt to address in a moment. First, let us examine the 
third important character in this short story, an English journalist who has come to West Germany to interview Helena. For the journalist, Helena relates a story that, we are told, 'has long ago ceased to be personal', a story that is both her own and somehow generic (Gallant 1974: 95). It is telling that this is all the narrator says about that story; that is, it is telling that the reader does not get the story itself. The reporter wants to know whether Helena was sexually molested as a child in the camps. The narrative point of view, as we have already noted, shifts subtly throughout the story, in a kind of varying selective omniscience, so that at times we catch a glimpse of the thought processes of the characters, without the narration slipping into the profusions of the confessional or, indeed, of testimony. When the reader comes to this episode with the English journalist, she finds the narrative shift in the direction of Helena's subjectivity, without the latter's thoughts trampling upon or splashing the calm, cool surface of the prose.

Rape is so important to these people, Helena has learned; it is the worst humiliation, the most hideous ordeal the Englishwoman can imagine. She is thinking of maniacs in parks, little children attacked on their way to the swimming pool. 'Destruction' is meaningless, and in any case Helena is here, alive, with her hair brushed, and blue on her eyelids not destroyed. But if the child were sexually molested, then we all know where we are. We will know that a camp was a terrible place to be, and that there are things Helena can never bring herself to tell. (Gallant I974: 95)

When Helena tells the reporter that no, this particular form of violence was never visited upon her, she detects a vague disappointment: the journalist becomes representative of a class of persons who appear interested in Helena's story, but who, if they do not betray the voyeurism of their interest, cannot interpret Helena's

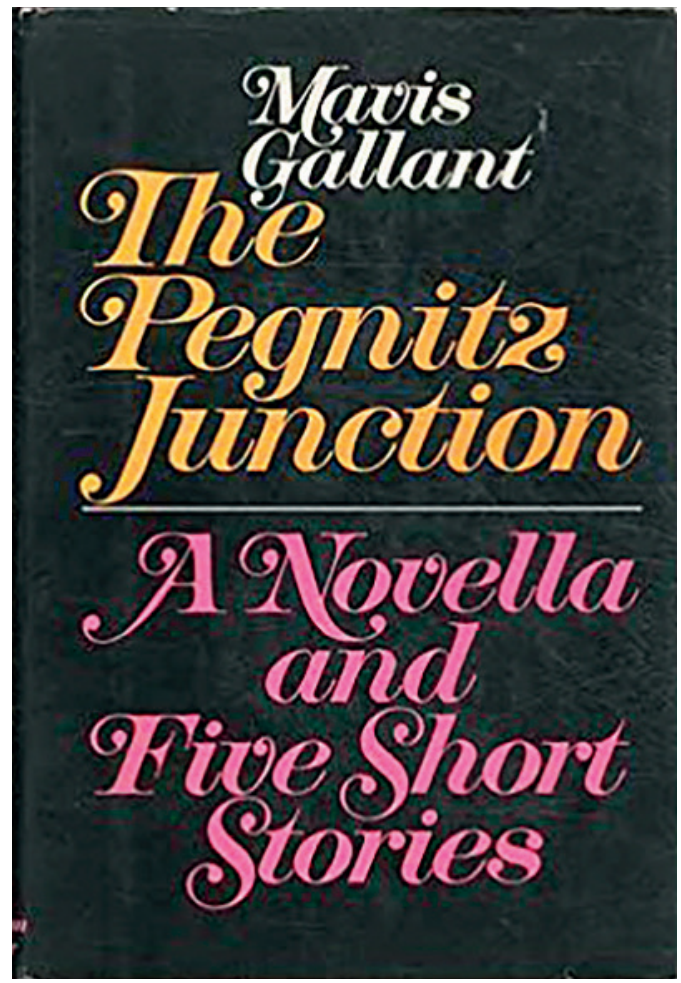

Five years after first appearing in The New Yorker, 'Old Friends' appeared in this collection of stories about post-war Germany.

story otherwise than by using their own fixed, pre-formed categories and images of trauma, who need these categories to 'know where they are': 'They want to know that it could not have been worse, but somehow it never seems bad enough' (Gallant r974: 95). Helena, it would seem, does not know where she is; the index of this can be found in the sentences that most insistently disturb the calm surface of the prose, containing, as they do, a stark statement of the unassimilated and persecutory trauma that she carries within her: 'Reality was confounded long ago. She even invents her dreams ... her true dream is of purification, of the river never profaned, from which she wakes astonished - for the real error was not that she was sent away but that she is here, in a garden, alive' (ibid. 92). With the end of that sentence, the narrative focus shifts to a retelling of the beginnings of 
this old friendship. The narrative structure is thus such that we get a fleeting indication of the intensity of the survivor's anguish and guilt, and with it, as the story moves on and changes focus, also her profound isolation.

So the inability to witness or to serve as a belated witness is not, for Gallant, a trait peculiar to German postwar culture. Indeed, in one respect, Helena appears to find her relationship with the unnamed police commissioner somehow less disturbing than the interactions she has with the kinds of inquiring minds typified by the journalist from England. 'Only her friend, the commissioner, accepts at once that [her experience in the camps] was beyond his imagination, and that the knowledge can produce nothing more than a pain like the suffering of laughter - like pleurisy, like indigestion' (Gallant I974: 92). But this recognition of the excessiveness of what Helena underwent, its unimaginability for someone who had led the life of a small-time official, comes with its own price, which we might call the avoidance of acknowledgment. When we ask what blocks the commissioner from witnessing the ongoing and anguishing effects of the camp experience in his friend Helena, we arrive at one of the most important, and complicated, questions for an interpretation of this story. On one level, and recognisably enough, what hinders the commissioner from entering into the kind of testimonial transaction that Helena needs but finds nowhere is an investment in a kind of bureaucratic rationalism, within the framework of which Helena's suffering can be designated an error:

he knows that where Helena was concerned a serious injustice was committed, a mistake ... he has gone over it so many times that her dossier is stamped on his mind, as if he had seen it, typed and signed, on cheap brownish wartime paper, in a folder tied with ribbon tape. To the dossier he adds: (I) she should never have been arrested. She was only a child.
(2) She is partly Jewish, but how much and which part - her fingers? Her hair? (3) She should never have been sent out of the country to mingle with Poles, Slovaks, and so on.

(Gallant I 974: 94)

What we see in this passage is that the West German commissioner tries to invent a coherent story within which Helena's suffering would make sense. This would be a story of her life that would also be a story that he wants to tell about the nation. But as Adam Phillips has written, viewed from a psychoanalytic perspective, 'however horrifying the facts ... history is always more horrifying - and so more elusive - than we can ever let ourselves know ... we make histories [of ourselves, of others, of nations] so as not to perish of the truth' (2014: 7). Moreover, in this passage, the commissioner never exits the framework of bureaucratic rationality, and moreover, never seems to consider the fact that such a framework might have limits. The trope of such a framework, which appears in this passage metonymically, through the references to the dossier, is of course a familiar enough one in artistic portrayals of the Third Reich and its aftermath.

What this story adds to this picture, complicating it somewhat, is the rather unusual nature of the friendship, at least in the commissioner's perception of it. At several moments in the text, it is suggested that the possible and perceived rejection of him by Helena would have the effect on him of a mother abandoning her child. As we are introduced to her, we read that Helena 'is younger than the commissioner, but if she were to turn away, dismiss him, withdraw her life, he would be the orphan. Yes, he would be an orphan of 53. It is the greatest possible anxiety he can imagine' (Gallant I974: 90). How are we to read this anxiety, on the part of the commissioner, about being orphaned by the German Jewish actress, an anxiety that, as Schaub points out, is ironic inasmuch as it is Helena who 'lost 
her mother in the camps'? It is significant that nowhere in the text is Helena figured in the activity of mothering or of having in some symbolic way given birth to the commissioner; she is only imaged as his mother through the threat of her absence, a threat that becomes especially palpable for him when she mentions having been in concentration camps during the war.

Without insisting too strongly upon a strict psychoanalytic reading of this story, I want to follow the theoretical lead of Levine and suggest that this particular figuration of the mother bears some of the marks of what Melanie Klein called 'splitting'. Most relevant from Klein's work here is the double relation to the mother (the famous good breast and bad breast for which Klein is perhaps best known); this is the phenomenon whereby the external object, of which the mother is both the most significant and the prototype for later relations, is 'split' into non-integrated good and evil parts, so that the mother is experienced as both loving and gratifying on the one hand, and frustrating and, and here we come to a term that is of great relevance for an interpretation of this story, persecutory. The commissioner experiences Helena's every mention of her life during the war years as a kind of persecution. Denial and idealisation are important aspects of the cycles constituting this same mechanism; in Klein's account of splitting, one denies that negative experiences have taken place, and one idealises and exaggerates the goodness of positive experiences to create a refuge from feared persecution. As Klein writes in a $195^{\circ}$ paper, idealization is used as a defense against persecutory anxiety and is its corollary' (1 975: 46). When we are told that Helena's words about the camps are taken by the commissioner as wounding, I think we can reasonably conclude that he experiences this 'part' of Helena - the part of her that is wounded and that gives voice to this wound, however minimally - as persecutory, and we could even extrapolate from this experience to suggest that he has unconsciously projected some hateful part of himself into this motherfigure, and that this hatred redounds upon himself in the form of the felt persecution. His idealisation of her can be seen in the following description of their exchange at the restaurant table: 'she is laughing, so she must be pleased. She is giving the commissioner her attention. On crumbs like these, her laughter, her attention, he thinks he can live forever' (Gallant r 974: 92) Here the commissioner appears childlike in the utmost, as desperately in need of his mother's attention for his well-being. In any case, this whole cycle of projection and idealisation forecloses the possibility for the kind of exchange that might facilitate working through on the part of Helena, or at the very least, to give her the chance to narrate her own stories on her own terms, and to have those stories taken in by an ear that is, to some extent, open.

In their particular relationship, the commissioner appears powerless to put things right between the actress and him. The possibility that he could make psychic reparations with her does not appear to enter into his deliberations. When Helena becomes the bad, persecuting, abandoning mother, the task of restoration or reparation lies completely in her hands. He sees himself as being at her mercy. It never occurs to him to ask her much of anything, much less to ask for something like forgiveness. At the end of the story, she confides in him at the garden restaurant table that she was, in fact, never raped in the camps. This bit of information is immediately interpreted by the commissioner as a kind of exoneration: 'he has come through, without being wounded. Whatever the quarrel was [the quarrel, that is, that he thinks led her to bring up the issue of the camps in the first place], he is forgiven ... She has, again, brought him out of anxiety and confusion; he is not an orphan' (Gallant 1974: 96).

It is tempting to read this story typologically, and there is indeed some textual warrant for seeing the main characters as types, that is, for 
seeing the story as a typological narrative about the politics of German-Jewish friendship in the ig6os, just as 'The Old Place' can be read as a typological commentary on American perceptions and modes of relating to the suffering of European Jews. In the case of 'The Old Friends', though, I am uncertain that such a reading is the only or even the best one. Instead, what seems to interest Gallant primarily in this story are the cultural-historical but also, I think, for her, universally human dynamics governing the ways in which we, avoiding acknowledging the stories of others, turning our eyes away from suffering (be it past or present), close off the space of testimonial transmission before it can open up.

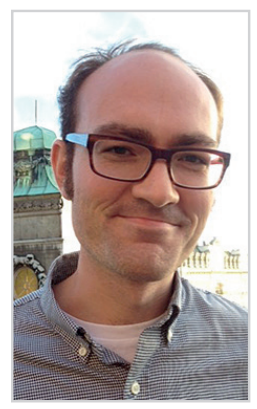

Joseph Ballan teaches English at an adult education centre (Komvux) and a technical college (Yrkeshögskola) in Helsingborg, Sweden. He received his doctorate from the Department of English, Germanic and Romance Studies at the University of Copenhagen in 2016 with a thesis on the poetry of Nelly Sachs. His publications include essays on asceticism, political theology, migration literature, Moses Mendelssohn and Søren Kierkegaard.

\section{References}

Arendt, Hannah, 2007. The Jewish Writings (New York, Schocken)

Ballan, Joseph, 20 I 5 . 'Regarding the refugee: Mavis Gallant's short fiction in the age of the exile', estrema: Revista Interdisciplinar de Humanidades, 6, pp. I $72-92$

Besner, Neil, I 988. The Light of Imagination (Vancouver, University of British Columbia Press)

Clement, Lesley D., 200o. Learning to Look: A Visual Response to Mavis Gallant's Fiction (London, McGill-Queen's University Press)

Condé, Mary, 2oor. 'Mavis Gallant and the politics of cruelty', The Yearbook of English Studies, 3 I, pp. I68-8 I

Gallant, Mavis, I 95 8. 'The Old Place', Texas Quarterly, I(2), pp. 66-80
- 1974. The Pegnitz Junction (London, Jonathan Cape)

I 986. Paris Notebooks (London, Bloomsbury)

Keefer, Janice Kulyk, I 989. Reading Mavis Gallant (Oxford, Oxford University Press)

Klein, Melanie, I975. The Writings of Melanie Klein: Envy and Gratitude and other works (London, Hogarth Press)

Laub, Dori, I 992. 'Bearing witness, or the vicissitudes of listening', in Testimony: Crises of Witnessing in Literature, Psychoanalysis, and History, ed. Shoshana Felman and Dori Laub (New York, Routledge), pp. 57-74

Levine, Michael, 2006. The Belated Witness: Literature, Testimony, and the Question of Holocaust Survival (Stanford, Stanford University Press)

Phillips, Adam, 20I4. Becoming Freud: The Making of a Psychoanalyst (London, Yale University Press)

Schaub, Danielle, r998. Mavis Gallant (New York, Twayne)

-2002. 'Mavis Gallant's irony and its destabilizing double edge: translating the exile's experience', in Varieties of Exile: New Essays on Mavis Gallant, ed. Nicole Côté and Peter Sabor (New York, Peter Lang), pp. I3-37 